\title{
Elimination of interharmonic currents by a FAP using the technique of compensation global
}

\author{
Mohamed Ali Moussa ${ }^{1}$, Bachir Belmadani², Ahmed Wahid Belarbi ${ }^{3}$, Rachid Taleb ${ }^{4}$ \\ ${ }^{1,3}$ Department of Electrotechnic, University of Sciences and Technology of Oran Mohamed-Boudiaf, Algeria \\ ${ }^{2,4}$ Laboratory of Electrical Engineering and Renewable Energy (LGEER), Chlef University, Algeria
}

\section{Article Info \\ Article history: \\ Received Jun 2, 2019 \\ Revised Jul 8, 2019 \\ Accepted Nov 3, 2019}

\section{Keywords:}

FMV

Interharmonics

Parallel active filter

Purity

\begin{abstract}
This document is a contribution to improve the quality of electrical energy in the distribution network. In this article we will present a method that allows us to clean up in a very considerable way the electrical network of both harmonics and inter harmonics provoked, basically by the ultrafast switches used when controlling a PWM inverter supplying a three-phase asynchronous motor. We notice that this method can be generalized for other loads creating inter-harmonics. This proposed method was simulated using the MATLAB/SIMULINK software and had given remarkable results (there is a considerable reduction in total harmonic distortion (THD) of source current from $29.52 \%$ to $0.82 \%$ )
\end{abstract}

This is an open access article under the CC BY-SA license.

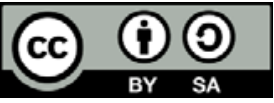

\section{Corresponding Author:}

Mohamed Ali Moussa,

Faculty of Electrical Engineering,

Department of Electrotechnic,

Applied Power Electronic Laboratory,University of Science and Technology of Oran Mohamed-Boudiaf, El Mnaouar, BP 1505, Bir El Djir 31000, Oran, Algéria.

Email: mohamed.alimoussa@univ-usto.dz

\section{INTRODUCTION}

The increasing use of the control systems based on electronic power causes more and more disturbance problems in the power grids. In fact, in addition to the harmonic disturbances, others called "inter-harmonic" perturbations (harmonics whose frequencies are non-integer multiples of the fundamental frequency) are mainly created by the non-linear loads connected to the network, especially by the converters of power (variators of speed, etc.) [1,2].

It should be noted that interharmonics are considered to be more harmful than harmonic components because they overlap to the fundamental wave and modify not only the shape of the current, but also the voltage, which results in the following adverse effects [3-5]. Interference with telecommunication networks: The electromagnetic coupling between the electrical and telecommunication networks can induce in these last important noises. The malfunctions of some electrical equipment: In the presence of interharmonics, the voltage (or the current) can change several times of sign in half a period. The risk of resonance excitation: The resonance frequencies of the circuits formed by transformer inductances and cables are normally high; The low frequency oscillations of mechanical systems; Disturbance of fluorescent lighting and electronic equipment; Interference with control and protection signals on power supply lines; Acoustic disturbances; The saturation of the intensity transformers.

In the literature, we find that many researchers have treated the problem of harmonics generated by loads such as rectifiers, alternators, transformers, fluorescent lamps, etc. But other loads such as 
asynchronous motors controlled by HF techniques can generate not only harmonics but also interharmonics $[6,7]$. Several techniques have been mentioned by researchers to combat the effects of interharmonics [8]. The most used is to install passive filters that attenuate the parasitic currents before they propagate in the network. But the main disadvantage of these devices, in addition to resonance they are not adapted to the variations of interharmonic spectra [8]. The new structures of network's depollution are emerged under name active filter $[3,9]$. The objective is then to adapt the filter in real time compared to the loads variations. In our work, we mainly focus on the reduction, and even the cancellation, of interharmonics resulting from the MLI control of an inverter which supplies a three-phase asynchronous motor by a parallel active filter (FAP) by using multi-filter variables (FMV) [10-12].

\section{RESOLUTION METHODOLOGY}

\subsection{Position of the problematic}

A three-phase asynchronous motor fed through a PWM inverter injects into the power grid, in addition to the harmonic currents, a lot of inter-harmonic currents that will deform the form of the voltage wave.

\subsection{Proposed solution}

We propose a solution that goes through two main stages.

\subsubsection{Identification of interharmonic currents}

To depollute the electrical network of these inter-harmonics, they must be identified with the best possible precision because the quality of the depollution resides in the efficiency of the method used for the identification of the inter-harmonic currents, several methods have been used by other researchers such as, the instantaneous power theory $[6,13,14]$ the synchronous reference theory $[15,16]$, the theory based on the bandpass filter [17-19]. In our work, we chose the method called "global FMV" (multi-variable filter) as shown in Figure 1.

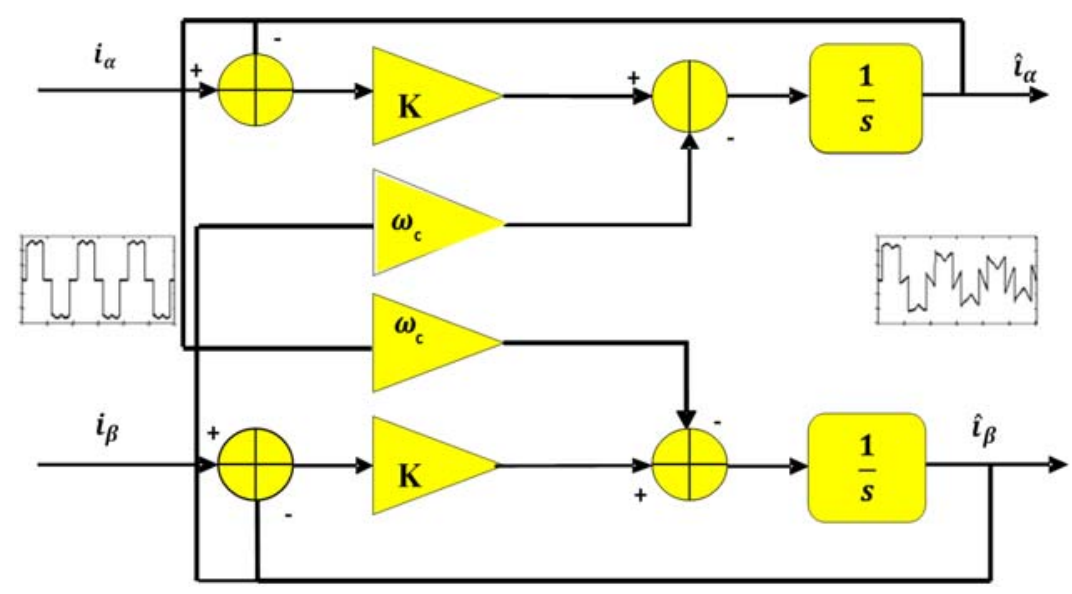

Figure 1. FMV circuit diagram

This filter essentially serves to separate the fundamental component of the load current $(\mathrm{f}=50 \mathrm{~Hz})$ of harmonic and inter-harmonic components $\left(\mathrm{f} \neq 50 \mathrm{H} \mathrm{z}\right.$ ), noted here $i_{\alpha h}$ et $i_{\beta h}$, exploiting the inverse transformation of Concordia [1, 20]. Indeed, the mathematical model of the FMV is developed in the first time by Song Hong-Scok, [9] the relation between the quantities of inputs and outputs having an integral effect as the expression shows it (formula (1)) [21, 22].

$$
i_{\alpha \beta}(s)=e^{j w_{c} t} \int e^{-j w_{c} t} \cdot i_{\alpha \beta}(t) d t
$$

After the transformation of Laplace, the (1) will have the form 


$$
H(s)=\frac{\hat{\imath}_{\alpha \beta}(s)}{i_{\alpha \beta}(s)}=\frac{s+j w_{c}}{s^{2}+w_{c}^{2}}
$$

By adding two new constants $k_{1}$ and $k_{2}$ in expression (2) it will become as follows

$$
H(s)=\frac{\hat{\imath}_{\alpha \beta}(s)}{i_{\alpha \beta}(s)}=K_{2} \frac{\left(s+K_{1}\right)+j w_{c}}{\left(s+K_{1}\right)^{2}+w_{c}^{2}}
$$

With:

$w_{c}$ : The cutoff pulse of the filter;

$K_{i}$ : positive constants;

$\mathrm{i}_{\alpha \beta}$ : The input currents of the FMV;

$\hat{\imath}_{\alpha \beta}$ : The output currents of the FMV;

For $\mathrm{H}(\mathrm{s})=0 d B$, it is necessary that:

$K_{1}=K_{2}=K$

Then

$$
\begin{aligned}
& \left.\hat{\imath}_{\alpha}=\frac{k}{s}\left[i_{\alpha}(s)-\hat{\imath}_{\alpha}(s)\right]-\frac{\omega_{c}}{s} \cdot \hat{\imath}_{\beta}(s)\right) \\
& \left.\hat{\imath}_{\beta}=\frac{k}{s}\left[i_{\beta}(s)-\hat{\imath}_{\beta}(s)\right]-\frac{\omega_{c}}{s} \cdot \hat{\imath}_{\alpha}(s)\right)
\end{aligned}
$$

\subsubsection{Compensation of interharmonic currents}

Once the interharmonic currents are identified, by subtracting on each axis $(\alpha-\beta)$ the output of the FMV at its input $(6)[4,6]$.

$$
\left\{\begin{array}{l}
i_{\alpha}=\hat{\imath}_{\alpha}+i_{h \alpha} \\
i_{\beta}=\hat{\imath}_{\beta}+i_{h \beta}
\end{array}\right.
$$

The reference interharmonic currents $\left(i_{\mathrm{c}_{-}}\right.$ref1,2,3) are obtained from the inverse transformation of Concordia

$$
\left[\begin{array}{l}
i_{c_{\text {_ref } 1}} \\
i_{c_{\text {_ref } 2}} \\
i_{c_{\text {_rref } 3}}
\end{array}\right]=\sqrt{\frac{2}{3}}\left[\begin{array}{cc}
1 & 0 \\
-1 / 2 & \sqrt{3} / 2 \\
-1 / 2 & -\sqrt{3} / 2
\end{array}\right]\left[\begin{array}{l}
i_{\alpha h} \\
i_{\beta h}
\end{array}\right]
$$

These reference currents are used to control the voltage inverter as shown in Figure 2. The operating principle of the parallel active filter is explained in the following section.

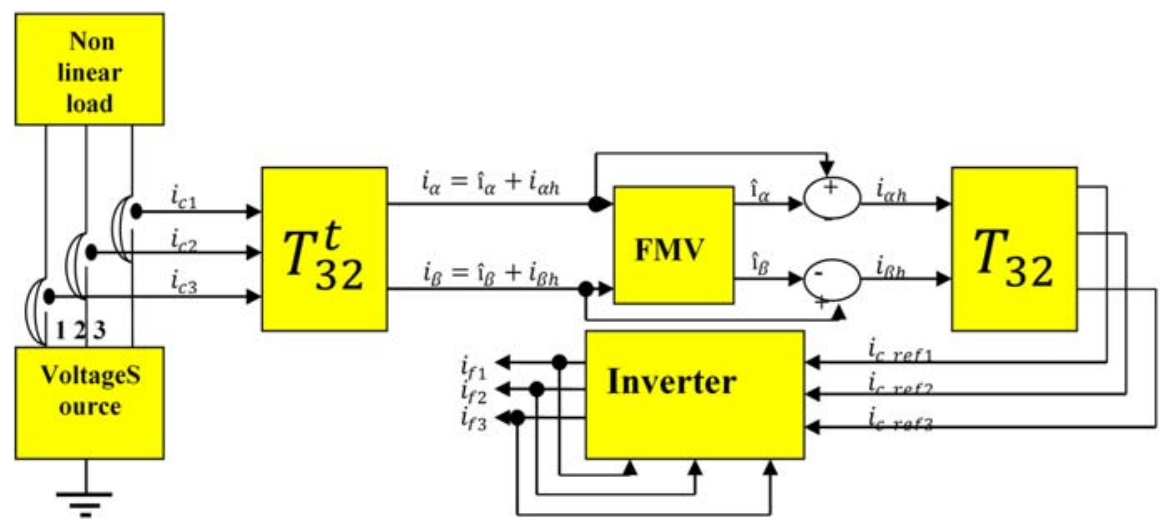

Figure 2. Algorithm for identifying inter-harmonic currents

\section{PRINCIPLE OF FUNCTIONING OF A PARALLEL ACTIVE FILTER (FAP)}

Our parallel active filter (FAP) is a voltage inverter with MLI; it is connected in parallel with the polluted load as shown in Figure 3. The control-command part is mainly based on the algorithm for identifying the inter-harmonic currents associated with the PWM algorithm [7, 18, 19]. Both of the 
algorithms contribute to the generation of filter control signals. The regulation of the DC bus voltage is guaranteed by the classical Proportional-Integral (PI) controller. The active filter produces inter-harmonic currents which are injected into the electrical network of the same amplitude but in opposition phase with the inter-harmonic currents caused by the load; this allows to eliminate the polluting inter-harmonics and to obtain the return for the form of linear current. Reacting quickly, the active filter improves the quality of the network power supply in real time for limiting the damages [10, 23-25].

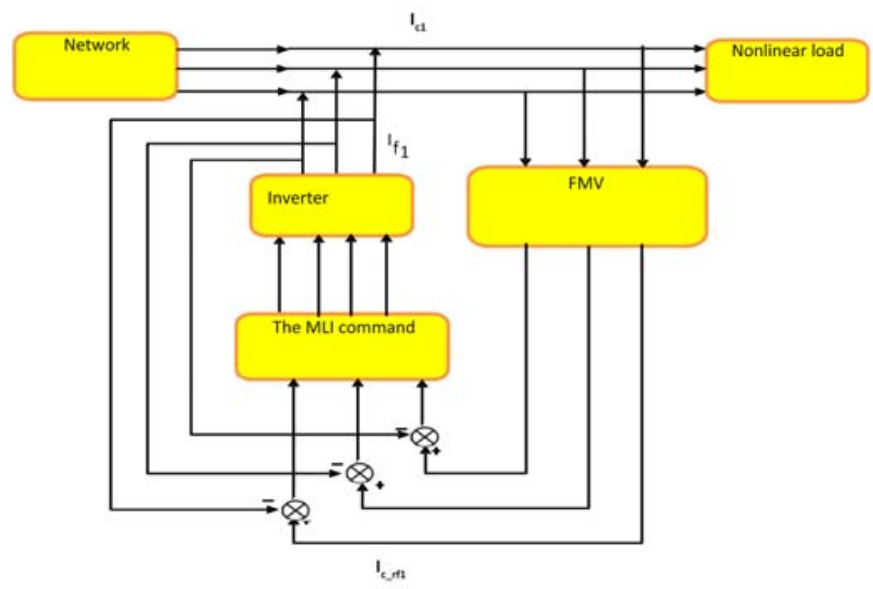

Figure 3. Principle function of the parallel active filter

\section{THE ANALYSIS OF RESULTS}

\subsection{Source current before filtering}

We note that our charge causes a significant degradation on the waveform of the current by generating harmonics and inter-harmonics of different frequencies; this degradation is translated by a high THD is worth $29.52 \%$. On the other hand, the proliferation of such a polluted current in the electrical network has a detrimental effect on the form of the voltage, hence the need to reduce the THD to acceptable values. Figure 4 to Figure 6 show the source current before filtering, source current spectrum before filtering, and the interharmonic current.

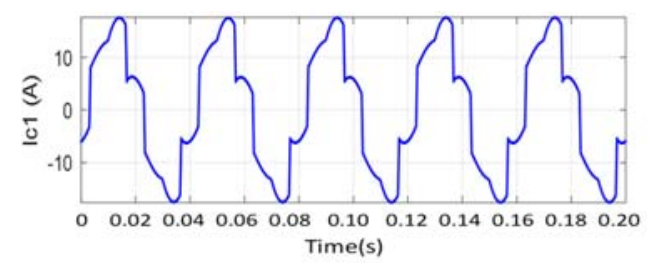

Figure 4. Source current before filtering

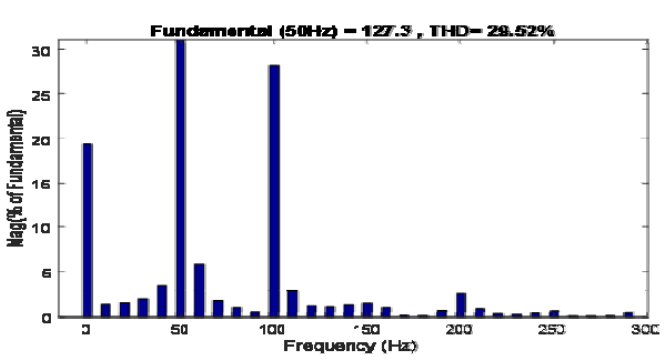

Figure 5. Source current spectrum before filtering

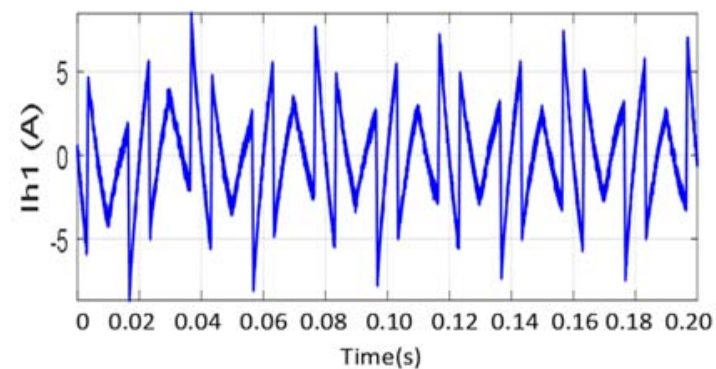

Figure 6. Interharmonic current

Elimination of interharmonic currents by a FAP using the technique ... (Mohamed Ali Moussa) 


\subsection{Source current after filtering}

After the filtering, the THD becomes $0.82 \%$, the harmonics and interharmonics took minimum values as shown in Figure 8, which confirms the efficiency of the technique used. Figure 7 shows the source current after filtering.

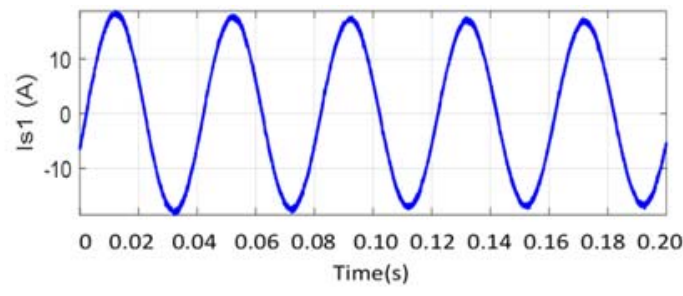

Figure 7. Source current after filtering

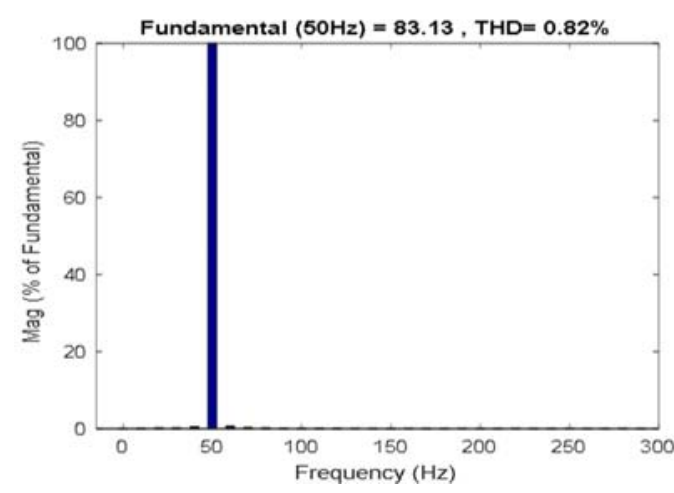

Figure 8 . The source current spectrum after filtering

\section{CONCLUSION}

In this paper we have put in place a method that allowed us to clean up the electrical network of harmonics and interharmonics generated by a three-phase asynchronous motors controlled by HF techniques (including MLI). The results of our study can be summarized in the following points: The use of a parallel active filter employing a multi-variable filter with the technique of global extraction of harmonics and interharmonics, which allows us to depollute the almost electrical network from all kind of parasite; The FMV identification method is very effective for extracting reference interharmonics and easy to implement; The FMV technique using the compensation global allows us to completely compensate the interharmonics of the network.

\section{REFERENCES}

[1] A. Testa, M. F. Akram, R. Burch, G. Carpinelli, G. Chang, et al., "Interharmonics: Theory and Modeling, IEEE Task Force on Harmonics Modeling and Simulation," IEEE Transactions on Power Delivery, Vol. 22, No 4, 2007.

[2] H. Atria, "Evaluation of selective harmonic elimination pulse width modulation technique for unipolar single faze H-bridge inverter: comparative study," International Journal of Power Electronics and Drive System (IJPEDS), Vol. 9, No. 3, 2018.

[3] Pablo Aravena, Luis Morán, Juan Dixon, and Geza Joos, "Active Compensation of Sub and Interharmonics in Cycloconverter-Fed Grinding Mill Drives," IEEE, 2010.

[4] K. Selvakumar1, et al., "Hysteresis Control 3-Level SI-NPC Inverter with Wind Energy System," International Journal of Power Electronics and Drive System (IJPEDS), Vol. 8, No. 4, pp. 1764-1770, 2017.

[5] B. Geethalakshmi, K. Babu, and S. Santhoshma, "Analysis of interharmonics in conventional and matrix converter fed adjustable speed drives," 2012 IEEE 5th India International Conference on Power Electronics (IICPE), 2012.

[6] Jing Yong, T. Tayjasanant, Wilsun Xu, and Caixin Sun, "Characterizing Voltage Fluctuations Caused by a Pair of Interharmonics," IEEE Transactions on Power Delivery, Vol. 23, No. 1, 2007.

[7] B. Geethalakshmi and S. Sivajanani, "Elimination of interharmonics in variable speed drives," International Conference on Advances in Engineering, Science and Management (ICAESM), pp. 804-809, 2012.

[8] A. Chebabhi, Fellah, M-K. Kessal A., Benkhoris, M-F. "The pq0 theory with multi variable filter and fuzzy logic control for a four leg shunt active power filter compensated by three dimensional space vector modulation under unbalanced loads," Engineering, Vol. 1, No. 15, pp.32-39, 2015.

[9] Sandeep kumar and Venu madhav, "Power quality improvement with a shunt active power filters using matlab / simulink," International Journal of Innovative Research in Electrical, Electronics, Instrumentation and Control Engineering (IJRITCC), Vol. 3, No. 1, 2015.

[10] Hsiung Cheng Lin, "Power Harmonics and Interharmonics Measurement Using Recursive Group-Harmonic Power Minimizing Algorithm," IEEE Transactions on Industrial Electronics, Vol. 59, No. 2, pp. 1184-1193, 2012.

[11] Jain, S.K. and Singh, S.N., "Exact Model Order ESPRIT Technique for Harmonics and Interharmonics Estimation," IEEE Transactions on Instrumentation and Measurement, Vol. 61, No. 7, pp. 1915 - 1923, 2012.

[12] Jin Hui, Wilsun Xu, and Honggeng Yang, "A Method to Determine the Existence of Genuine interharmonics," IEEE Transactions on Power Delivery, Vol. 27, pp. 1690-1692, 2012. 
[13] Langella, R., Testa, Alfredo, Emanuel, A.E., "Unbalance Definition for Electrical Power Systems in the Presence of Harmonics and Interharmonics," IEEE Transactions on Instrumentation and Measurement, Vol. 61, No. 10, pp. $2622-2631,2012$.

[14] Hooshyar, A., Azzouz, M.A., El-Saadany, E.F., "Addressing IEC Flickermeter Deficiencies by Digital Filtration Inside a Sliding Window," IEEE Transactions on Instrumentation and Measurement, Vol. 62. No. 9, pp. 2476 2491,2013

[15] Cheng-I Chen and Yeong-Chin Chen, "Comparative Study of Harmonic and Interharmonic Estimation Methods for Stationary and Time-Varying Signals," IEEE Transactions on Industrial Electronics, Vol. 61, No. 1, pp. 397 - 404, 2014.

[16] Sang-Wook Sohn, Young-Bin Lim, Jae-Jun Yun, Hun Choi, and Hyeon-Deok Bae, "A Filter Bank and a SelfTuning Adaptive Filter for the Harmonic and Interharmonic Estimation in Power Signals," IEEE Transactions on Instrumentation and Measurement, Vol. 6, No. 1 ,pp. 64 - 73, 2012.

[17] Yap Hoon, M. Amran Mohd Radzi, M. Khair Hassan, and N. Farzilah Mailah, "Control Algorithms of Shunt Active Power Filter for Harmonics Mitigation," Energies, 2018.

[18] José Luis Monroy-Morales, David Campos-Gaona, Máximo Hernández-Ángeles, Rafael Peña-Alzola and José Leonardo Guardado-Zavala, "An Active Power Filter Based on a Three-Level Inverter and 3D-SVPWM for Selective Harmonic and Reactive Compensation," Energies, 2017.

[19] Singh, Bhim; Al-Haddad, K.; Chandra, A., "A review of active filters for power quality improvement," IEEE Transactions on Industrial Electronics, Vol.46, No.5, pp. 960-971, 1999.

[20] A.ben abdelkader O. Abdelkhalek and A. Allali, "Experimental Validation of Single Phase Series Active Power Filter Using Fuzzy Control Technique," International Journal of Power Electronics and Drive Systems (IJPEDS), Vol. 9, No. 2, pp. 591-601, 2018.

[21] D. M. Soomro, S. C. Chong, Z. A. Memon, F. Abbasi, "Power Quality Improvement in QUCEST Larkana Campus by Using Three Types of Power Filters", International Journal of Power Electronics and Drive Systems (IJPEDS), Vol. 8, No. 4, pp. 1876-1885, 2017.

[22] Thirumoorthi, P and T D, Raheni, “Adaptive Method for Power Quality Improvement through Minimization of Harmonics Using Artificial Intelligence," International Journal of Power Electronics and Drive Systems (IJPEDS), Vol. 8, No. 1, pp. 470-482, 2017.

[23] S. Qin, et al., "A high power density series-stacked energy buffer for power pulsation decoupling in single phase converters," IEEE Transactions on Power Electronics, Vol. 32, No. 6, 2017.

[24] A. U. Lawan, "State Feedback Approaches for Designing a Statcom Supplementary Controller for Oscillations Damping," Int. J. Eng. Sci., Vol. 3, No. 7, pp. 27-37, 2014.

[25] M. Zhang, L. Huang, W. Yao, and Z. Lu, "Circulating harmonic current elimination of a CPS-PWM-based modular multilevel converter with a plug-in repetitive controller," IEEE Trans. Power Electron., Vol. 29, No. 4, pp. 20832097, 2014.

\section{BIOGRAPHIES OF AUTHORS}

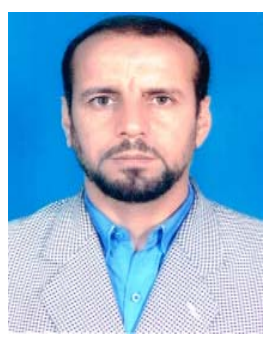

Mohamed ALI MOUSSA is a teacher researcher in Chlef University (Algeria); he received his Engineer's Degree in Electrical Engineering in 1997 from the University of Laghouat (Algeria). He defended his Magister degree in electrical engineering in 2013 at the University of Khemis-Mliana (Algeria). He is now preparing his doctorate at the University of Science and Technology of Oran (Aleria). His area of scientific interest is the study of interharmonics in the electrical network. E-mail: mohamed.alimoussa@univ-usto.dz

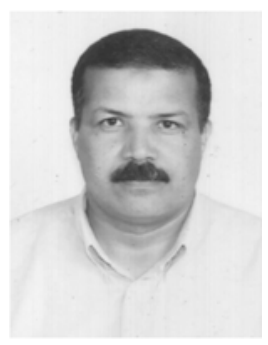

Professor Bachir BELMADANI received the B.S. degree in Electrical Engineering from the Mohamed Boudiaf University of Science and Technology, Oran, Algeria, in 1985, and the $\mathrm{PhD}$ degree from the Paul Sabatier University of Toulouse, France, in 1989. He is currently Professor of Power Electronics in Chlef University, Ouled Fares, Algeria. He is the Director of the Laboratory of Electrical Engineering and Renewable Energy and the Vice Rector for external relations with Chlef University. His research interests include power electronics, electrical drives and renewable energies. He has authored several international publications. His current research interests include power electronics, thermal and non-thermal plasmas and their applications, modeling and simulation of converters, field-programmable gate array, DSP, and intelligent control. E-mail: belmadanibachir@gmail.com 


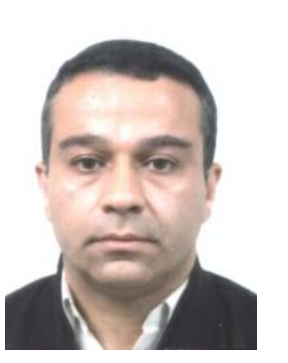

Professor Ahmed Wahid BELARBI was born in 1965.He received the B.E degree in electrical engineering from University of Science and Technology of Oran in 1989, the PhD degree from Paul Sabatier University, Toulouse III, French, in 1994.He works at University of Science and Technology of Oran, Algeria since 1996; he is a professor of the Faculty of Electrical Engineering and head of research team at Applied Power Electronic Laboratory. His research interests. E-mail: Baw_dz@yahoo.com

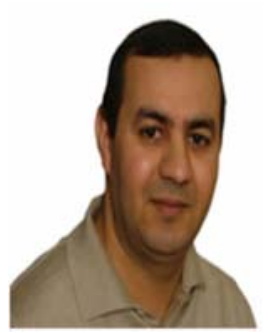

Professor Rachid TALEB received the M.S. degree in electrical engineering from the Hassiba Benbouali University, Chlef, Algeria, in 2004 and the Ph.D. degree in electrical engineering from the Djillali Liabes University, Sidi Bel-Abbes, Algeria, in 2011. Currently he is a professor with the Department of Electrical Engineering, Hassiba Benbouali University. He is a team leader in the LGEER Laboratory (Laboratoire Génie Electrique et Energies Renouvelables). His research interest includes intelligent control, heuristic optimization, control theory of converters and converters for renewable energy sources. E-mail: rac.taleb@gmail.com 